\title{
Mathematical and Kinetic Modelling of the Adsorption of Crude Oil Spill Using Coconut Coir Activated Carbon
}

\author{
Ukpong Anwana Abel ${ }^{1, ~ *, ~ G u m u s ~ R h o d a ~ H a b o r ~}{ }^{2}$, Oboh Innocent Oseribho ${ }^{3}$ \\ ${ }^{1}$ Department of Chemical and Petrochemical Engineering, Akwa Ibom State University, Ikot Akpaden, Nigeria \\ ${ }^{2}$ Department of Petroleum and Chemical Engineering, Niger Delta University, Wiberforce Island, Nigeria \\ ${ }^{3}$ Department of Chemical and Petroleum Engineering, University of Uyo, Uyo, Nigeria
}

Email address:

anwanaukpong@aksu.edu.ng (U. A. Abel), rhodagumus@yahoo.com (G. R. Habor), innocentoboh@uniuyo.edu.ng (O. I. Oseribho)

${ }^{*}$ Corresponding author

\section{To cite this article:}

Ukpong Anwana Abel, Gumus Rhoda Habor, Oboh Innocent Oseribho. Mathematical and Kinetic Modelling of the Adsorption of Crude Oil Spill Using Coconut Coir Activated Carbon. Journal of Energy, Environmental \& Chemical Engineering. Vol. 6, No. 1, 2021, pp. 1-9. doi: 10.11648/j.jeece.20210601.11

Received: October 9, 2020; Accepted: October 26, 2020; Published: January 12, 2021

\begin{abstract}
Crude oil spills have tremendous effects on our environment and poses severe pollution problems around the world as hazardous chemicals such as polycyclic aromatic hydrocarbons are released into the ecosystem. The clean-up of these spills using natural adsorbent is considered as an eco-friendly and cost effective method of handling the oil spills due to its high oil sorption capacity and biodegradability. Coconut coir predominantly found in the Niger Delta area of Nigeria was carbonized and chemically activated using Potassium Hydroxide $(\mathrm{KOH})$ for the removal of crude oil spill. The kinetic data were fitted into various kinetic models with Pseudo-second order model showing best fit with a correlation coefficient $\mathrm{R}^{2}=0.999$ and the Boyd model revealed that the adsorption was controlled by internal transport mechanism and film-diffusion was the major mode of adsorption. Thus, Coconut Coir Activated Carbon (CCAC) showed significant capability to be used as a low-cost, re-generable and eco-friendly adsorbent in oil spill clean-up. A mathematical model was also developed using multivariate numerical optimization method and was validated by fitting it into the experimental data which gave a correlation coefficient $\mathrm{R}^{2}=0.997$. Hence, the empirical model developed using multivariate numerical optimization method can be used for the design of industrial treatment plant.
\end{abstract}

Keywords: Coconut Coir, Multivariate Numerical Optimization, Non-linear Regression, Crude Oil Removal, Batch Adsorption, Adsorbent

\section{Introduction}

The progressive increase in industrialization and the continuous reliance on petroleum hydrocarbons for energy generation has led to numerous cases of accidental crude oil spill due to the increase in production, exploration, transportation, distribution, storage and other related processes of crude oil. As a result, oil spills have become a worldwide concern due to its environmental and economic impact [1-3]. The release of hazardous chemicals such as Polycyclic Aromatic Hydrocarbons (PAHs), Benzene, Toluene, Ethylbenzene, and Xylene (BTEX) from oil spills have adverse effect to aquatic and human lives and may require longer time before the effect can be reversed [4].
Apart from financial losses due to shut-down of production facilities as a result of pipeline vandalization [5], fire explosion leading to loss of lives and properties [6]; such incidents cause huge and sustained devastation in Earth's ecosystems and harm living organisms [7]. The Niger Delta landscape of Nigeria is criss-crossed with pipelines and punctuated with pumping stations that connect the over 600 oilfields with storage facilities and tanker loading ports. These installations and the spills are often in close proximity to villages which usually leads to oil spillage contaminating agricultural fields, fishing areas and drinking-water sources. The ecological effects have only been spot-wise investigated, but those few studies and the preponderance of oil on-land and water makes it obvious that the impact is massive [8]. These environmental disasters together with some local scale 
incidents seriously endanger the environment; thus, it has become imperative in improving oil spill clean-up methods and developing new materials which can be applied for this purpose. A number of mechanical, biological, chemical and adsorption methods are currently used to remove oil spill from water [9]. Among these several chemical and physical methods, the adsorption onto activated carbon has been found to be superior to other techniques because of its capability for adsorbing a broad range of different types of adsorbate efficiently; and its simplicity of design [10,3]. However, commercially available activated carbons are still considered expensive [11]. Consequent upon this, many researchers have resorted to studying cheaper substitutes, which are inexpensive, and are endowed with reasonable adsorptive capacity.

Adsorption technique has been proven to be an efficient and economical process for the treatment of oil spillage and are currently used to remove oil spills from water media and paved roads, remove volatile hydrocarbons [12] and Benzene, Toluene, Ethylbenzene and Xylene (BTEX) present in water soluble fraction (WSF) of crude oil [13-15]. The most popular method of adsorption technique involves the use of various kinds of adsorbent; especially during rescue operations on water bodies. A comprehensive rescue operation is aimed at efficient removal of oil spills from the water surface, coastal zones and at preventing further migration of these contaminants. The efficiency of the process lies in the choice of suitable/ideal adsorbent with the following characteristics: oleophilicity, buoyancy, biodegradable/renewable, high adsorption/retention capacity, environmentally-friendly, cheap and readily available [3]. In recent times, a number of agricultural waste products such as male flower of coconut tree [16], jute fibre [17], rubber wood sawdust [18], corncob [19], bamboo [20] and oil palm fibre [21] have been successfully utilized as renewable and cheaper precursors for the production of activated carbons for adsorption of oil-in-water.

Adsorption kinetics describes the rate of retention or release of a solute from an aqueous environment to solidphase interface at a given adsorbents dose, temperature, flow rate and $\mathrm{pH}$. During adsorption two main processes are involved; physical (physisorption) or chemical (chemisorption). Physical adsorption is as a result of weak forces of attraction (van der Waals), while chemisorption involves the formation of a strong bond between the solute and the adsorbent that involves the transfer of electrons. The kinetic equations of the chemical reaction show the dependence of the reaction rate on the concentrations of the reactants which is determined from data obtained experimentally. The study of adsorption kinetics is important because it provides valuable information and describes the mechanism of the reaction and also helps to determine the overall rate of the adsorption process [22].

In recent times, linear regression analysis has been among the most pronounced and viable tools frequently applied for analysis of experimental data obtained from adsorption process. It has been used to define the best fitting relationship that quantify the distribution of adsorbates, verification of the consistency of adsorption models and the theoretical assumptions of adsorption models [23, 24]. Several mathematically rigorous error functions have been used to drastically address the inherent biasness in the error structure of experimental data resulting from the transformation of adsorption isotherms into their linearized forms $[25,26]$. It is against this backdrop that non-linear regression analysis becomes inevitable, since it provides a mathematically rigorous method for determining adsorption parameters using original form of isotherm equations [27, 28]. Unlike linear regression, nonlinear regression usually involved the minimization or maximization of error distribution between the experimental data and the predicted isotherm based on its convergence criteria [29].

In the aspect of engineering and science, modelling can be referred to the process of identifying objective, variables and constraints for a given problem. Formulation of an appropriate model that describes the problem (process) is the first and most important step in the optimization process. Once the model is formulated, an optimization algorithm can be used to find its solution.

Generally, models and algorithms are complicated; hence computer simulation is required to implement the optimization process. Multivariate numerical optimization means optimization of a scalar function of several variables. Mathematically, optimization is simply the minimization or maximization of an objective function, constraints on its variables. Sometimes, it is usually the user's responsibility to choose an algorithm that is most appropriate for the specific problem [30]. This is important as it determines whether the problem is solved rapidly or slowly and indeed the solution is found at all.

In numerical optimization, the fastest algorithm seeks only a local solution; which is referred to as local optimal. Basically, this is the point at which the objective function is smaller than all other feasible point in its vicinity. Global solution (global optimal) is simply referred to as the best of all the minima of the objective function $[30,31]$.

Most numerical optimization algorithms are iterative and simply begin with an initial guess to be optimal values of the variables and a sequence of improved estimates is generated until a final solution is reached. The strategy used to move from one iterate to the next distinguishes the algorithm from another and most strategies make use of the values of the objective function and constraints with possibly the first and second derivatives of these functions [30]. Some algorithms accumulate information gathered at previous iteration while others use only local information from current point. Regardless of these specifics, algorithms should be robust, efficient and accurate [32]. There are several developed optimization approaches in the literature to perform this iterative estimation namely Gauss-Newton, Steepest Descent, Marquardt-Levenberg, Nelder-Mead, General Reduced Gradient (GRG) protocol, among others [33, 30, 31].

Mathematical modelling and computer simulation of adsorption offers an extremely powerful tool for a number of 
tasks on different levels. It is essential for process design and optimization where the equilibrium and dynamic test information comes together representing a multivariable system which cannot be effectively handled without appropriate modelling and computer-based techniques. When reaction kinetics is combined with mass transfer that is, in turn, dependent on the particle and fluid flow properties only a rather sophisticated apparatus can make sense out of the web of variables. Hence, the purpose of this research is to develop an empirical model using multivariate numerical optimization method to predict the adsorption process performance under different conditions where computer simulations can then replace numerous tedious and costly experiments.

\section{Experimental Methods}

\subsection{Preparation of Adsorbent}

The procedure for preparing coconut coir activated carbon (CCAC) is explicitly expatiated in Ukpong et al. (2020) [3]. The coconut coir was obtained from Etinan main market in Etinan LGA, Akwa Ibom State, Nigeria and were washed with distilled water; thereafter dried to constant weight at $105^{\circ} \mathrm{C}$ for $24 \mathrm{~h}$ in a laboratory drying oven (DHG-9101 model) to remove excess water content and some volatile components. The dried sample was then crushed and sieved into smaller size particle $(1-2 \mathrm{~mm})$ and stored at room temperature. The crushed coconut coir sample was carbonized in a muffle furnace at a temperature of $600^{\circ} \mathrm{C}$ for $2 \mathrm{~h}$ in the absence of oxygen and the carbonized sample was activated with $\mathrm{KOH}$ pellets at an Impregnation Ratio (I. R) of 1:2. The mixture was then dried in a laboratory drying oven at $105^{\circ} \mathrm{C}$ for $12 \mathrm{~h}$ to remove moisture and was further heated in a muffle furnace at a temperature of $800{ }^{\circ} \mathrm{C}$ for $1 \mathrm{~h}$ to complete the activation process. The coconut coir activated carbon (CCAC) produced was cooled to room temperature and washed with $0.1 \mathrm{M} \mathrm{HCl}$ solution to remove any residual ash content and with distilled water until the $\mathrm{pH}$ of washing solution reached 6-7. The prepared CCAC was then oven dried at temperature of $105^{\circ} \mathrm{C}$ for $2 \mathrm{~h}$ and further crushed and sieved into $63-500 \mu \mathrm{m}$ particle sizes and then stored in a desiccator until needed for the adsorption experiment.

\subsection{Batch Adsorption Kinetics Studies}

The batch adsorption kinetics study as reported by Ukpong et al. (2020) was carried out by measuring $250 \mathrm{~mL}$ of the simulated oil spill of $19440 \mathrm{mg} / \mathrm{L}$ initial concentration into a $500 \mathrm{~mL}$ beaker for each experimental run and $1.0 \mathrm{~g}$ of $\mathrm{CCAC}_{\mathrm{KOH}}$ was measured into the simulated oil spill while being agitated in an orbital shaker (Rotamax 120, Reidolph) at $20 \mathrm{rpm}$ and at a temperature of $25^{\circ} \mathrm{C}$ for varying contact time of $(15,30,45,60,75,90,105$ and $120 \mathrm{~min})[3,34]$.

\subsection{Development of Mathematical Model}

Aryafar et al. (2019) applied non-linear multivariate regression analysis to develop mathematical equations for the adsorption kinetics which relate the adsorption process with many factors such as the contact time, $\mathrm{pH}$, solution concentration, and adsorbent mass [35].

The mathematical model for the batch adsorption is potentially affected by the external film resistance and the surface mass transfer resistance. The batch surface diffusion model was based on the following assumptions:

The porous adsorbent particles are perfectly spherical containing reacting sites that are homogeneously distributed within them [36].

The reaction of the adsorbent particles is governed by a chemisorption mechanism [37].

The system is perfectly mixed, so the external mass transfer process occurs solely in a thin boundary layer surrounding the particles.

The aqueous phase is an isothermal process and having fast intrinsic adsorption kinetics [38].

The equilibrium process is described by the Langmuir adsorption isotherm [37].

The diffusion coefficient is constant during the adsorption process.

The $\mathrm{pH}$ of the external phase is constant with time.

For the development of the correlation in this study, the Adsorption capacity (A. C) depends directly proportional to both contact time and initial concentration as shown in Eqs. (1) and (2) and also indirectly proportional to the adsorbent mass as shown in Eq. (3). Based on this assertion, the relationship of $\mathrm{A}$. $\mathrm{C}$ with the adsorption parameters are presented in Eqs. (1) to (3).

$$
\begin{aligned}
\text { A. } C & \propto \mathrm{t} \\
\text { A.C } & \propto \mathrm{C}_{0} \\
\text { A. } C & \propto \frac{1}{M}
\end{aligned}
$$

The Adsorption capacity (A. C) can also be expressed as a function of the aforementioned parameters in Eq. (4).

$$
\text { A.C }=f\left(\mathrm{t}, \mathrm{C}_{\mathrm{o}}, \mathrm{M}\right)
$$

However, Eqs. (1) to (3) can be expanded in the basic form of non-linear multivariate algebraic expression as given in Eq. (5).

$$
\text { A.C }=\beta_{\circ}\left(t^{\beta 1} \times C_{o}^{\beta_{2}} \times M^{-\beta 3}\right)
$$

Alternatively, Eq. (5) can also be expressed as Eq. (6).

$$
A \cdot C=\beta_{\circ}\left[\frac{t^{\beta_{1}} \times C_{o}^{\beta_{2}}}{M^{\beta_{3}}}\right]
$$

By applying the logarithmic transformation to linearize Eq. (6), we obtain Eq. (7). 
$\operatorname{LOG}($ A.C $)=\operatorname{LOG}\left(\beta_{\circ}\right)+\left[\left(\beta_{1} \operatorname{LOG}(\mathrm{t})+\beta_{2} \operatorname{LOG}\left(\mathrm{C}_{0}\right)\right)-\beta_{3} \operatorname{LOG}(\mathrm{M})\right]$

where $\beta_{\mathrm{o}}$ is the adsorption coefficient while $\beta_{1}, \beta_{2}$ and $\beta_{3}$ are exponential constants of the adsorption parameters.

The variables $\beta_{\mathrm{o}}, \beta_{1}, \beta_{2}$ and $\beta_{3}$ can be determined iteratively using multivariate numerical optimization method. To perform this iterative estimation, several approaches can be employed to determine these variables such as Gauss-Newton, NelderMead, Marquardt-Levenberg, steepest descent and General Reduced Gradient (GRG) protocol and the adsorption parameters (contact time, initial concentration and adsorbent mass) are also obtained experimentally [33, 30, 31].

The unknown adsorption coefficient $\left(\beta_{\mathrm{o}}\right)$ and the exponential constants $\left(\beta_{1}, \beta_{2}\right.$ and $\left.\beta_{3}\right)$ are solved iteratively using GRG protocol in the Microsoft Excel SOLVER [33]. To validate this correlation, the predicted data obtained are compared with the experimental data and other established models. Also, the goodness of fit of the predicted data to that of the experimental data is established using coefficient of determination $\left(\mathrm{R}^{2}\right)$ and other error functions.

\subsection{Adsorption Kinetics Models}

Some of the kinetic models that were selected for fitting to the experimental data under study are as shown in Table 1. The parameters were determined using non-linear regression method.

Table 1. Kinetic models for the Adsorption process.

\begin{tabular}{llll}
\hline S/N & Kinetic Model & Model Equation & References \\
\hline 1. & Pseudo First Order Model & $\mathrm{q}_{\mathrm{t}}=\mathrm{q}_{\mathrm{e}}\left(1-\mathrm{e}^{-\mathrm{k} \mathrm{t}}\right)$ & [39] \\
2. & Pseudo Second Order Model & $\mathrm{q}_{\mathrm{t}}=\frac{\mathrm{k}_{\mathrm{s}} \mathrm{q}_{\mathrm{e}} \mathrm{t}}{1+\mathrm{k}_{\mathrm{s}} \mathrm{et}}$ & {$[40,41]$} \\
3. & Intra-particle Diffusion Model & $\mathrm{q}_{\mathrm{t}}=\mathrm{K}_{\mathrm{p}} \sqrt{\mathrm{t}}+\mathrm{C}$ & {$[42-44]$} \\
& & $0.86 \leq \mathrm{F} \leq 1: \mathrm{B}_{\mathrm{t}}=-0.4977-\operatorname{In}(1-\mathrm{F})$ & {$[45,46]$} \\
4. & Boyd Diffusivity Model & $\mathrm{F}=\frac{\mathrm{q} \mathrm{t}}{\mathrm{q}_{\infty}}$ & \\
\hline
\end{tabular}

$\mathrm{K}_{1}, \mathrm{~K}_{\mathrm{s}}$ and $\mathrm{K}_{\mathrm{p}}$ are model constants.

\subsection{Statistical Analysis}

Nonlinear regression of kinetic models usually contains error between the experimental data and the predicted model. Therefore, several mathematically rigorous error functions were investigated as shown in Table 2.

Table 2. Statistical measures used in determining the goodness of fit for the Kinetic models.

\begin{tabular}{|c|c|c|c|}
\hline $\mathbf{S} / \mathbf{N}$ & Error Function & Equation & References \\
\hline 1. & The Sum Square of Errors (ERRSQ) & ERRSQ $=\sum_{\mathrm{i}=1}^{\mathrm{n}}\left(\mathrm{q}_{\mathrm{e}, \mathrm{exp}}-\mathrm{q}_{\mathrm{e}, \mathrm{cal}}\right)^{2}$ & {$[47,48]$} \\
\hline 2. & Hybrid Fractional Error Function (HYBRID) & HYBRID $=\frac{100}{n-p} \sum_{i=1}^{n}\left[\frac{\left(q_{e, e x p}-q_{e, c a l}\right)^{2}}{q_{e, e x p}}\right]$ & {$[49,50]$} \\
\hline 3. & Average Relative Error (ARE) & $\operatorname{ARE}=\frac{100}{\mathrm{n}} \sum_{\mathrm{i}=1}^{\mathrm{n}}\left|\frac{\mathrm{q}_{\mathrm{e}, \mathrm{exp}}-\mathrm{q}_{\mathrm{e}, \mathrm{cal}}}{\mathrm{q}_{\mathrm{e}, \mathrm{exp}}}\right|$ & {$[49,50]$} \\
\hline 4. & Marquardt's Percent Standard Deviation (MPSD) & MPSD $=100 \sqrt{\frac{1}{n-p}} \sum_{i=1}^{p}\left(\frac{q_{e, e x p}-q_{e, c a l}}{q_{e, e x p}}\right)_{i}^{2}$ & [49] \\
\hline 5. & Sum of Absolute Errors (EABS) & EABS $=\sum_{i=1}^{p}\left|q_{e, e x p}-q_{e, c a l}\right|$ & [51] \\
\hline 6. & Coefficient of Determination $\left(R^{2}\right)$ & $\mathrm{R}^{2}=\frac{\sum\left(\mathrm{q}_{\mathrm{e}, \exp }-\overline{\mathrm{q}_{\mathrm{e}, \text { cal }}}\right)^{2}}{\sum\left[\left(\mathrm{q}_{\mathrm{e}, \exp }-\overline{\mathrm{q}_{\mathrm{e}, \text { cal }}}\right)^{2}+\left(\mathrm{q}_{\mathrm{e}, \mathrm{exp}}-\mathrm{q}_{\mathrm{e}, \text { cal }}\right)^{2}\right]}$ & {$[52,53]$} \\
\hline 7. & Nonlinear Chi-Square Test $\left(\chi^{2}\right)$ & $\chi^{2}=\sum_{\mathrm{i}=1}^{\mathrm{n}} \frac{\left(\mathrm{q}_{\mathrm{e}, \exp }-\mathrm{q}_{\mathrm{e}, \mathrm{cal}}\right)^{2}}{\mathrm{q}_{\mathrm{e}, \exp }}$ & {$[54,55]$} \\
\hline
\end{tabular}

Where, $\mathrm{q}_{\mathrm{e}, \mathrm{cal}}$ is the theoretical concentration of adsorbate on the adsorbent, which have been calculated from one of the isotherm models, $\mathrm{q}_{\mathrm{e}, \mathrm{exp}}$ is the experimentally measured adsorbed solid phase concentration of the adsorbate adsorbed 
on the adsorbent. $(n)$ is the number of data points, $(p)$ is the number of parameters in the equation.

\section{Results and Discussion}

\subsection{Batch Adsorption Kinetics}

Several kinetic models such as the pseudo-first order, pseudo-second order, intra-particle diffusion and Boyd models were used to study the kinetic behaviour and mechanism for the crude oil adsorption process. The adsorption kinetic model constants for the removal of crude oil are shown in Table 3 and the results showed that the coefficient of determination for the pseudo-second order kinetic model for $\mathrm{CCAC}_{\mathrm{KOH}}\left(\mathrm{R}^{2}=0.999\right)$ was much higher and closer to unity than that of pseudo-first order kinetic model and intra-particle diffusion, thus; the adsorption behaviour of crude oil on $\mathrm{CCAC}_{\mathrm{KOH}}$ predominantly followed pseudo-second order kinetic model.

Table 3. Adsorption kinetic model constants for the removal of crude oil using $C$ CAC ${ }_{K O H}$.

\begin{tabular}{|c|c|c|c|c|c|c|c|}
\hline \multirow{2}{*}{ Adsorbent } & \multirow{2}{*}{$q_{\mathrm{e}, \exp }(\mathrm{mg} / \mathrm{g})$} & \multicolumn{3}{|c|}{ Pseudo-first order } & \multicolumn{3}{|c|}{ Pseudo-second order } \\
\hline & & $\mathrm{K}_{\mathrm{f}}(\mathrm{g} / \mathrm{mg} \cdot \mathrm{min})$ & $\mathrm{q}_{\mathrm{e}, \mathrm{cal}}(\mathrm{mg} / \mathrm{g})$ & $\mathrm{R}^{2}$ & $\mathrm{~K}_{\mathrm{s}}(\mathrm{g} / \mathrm{mg} \cdot \mathrm{min})$ & $\mathrm{qe}_{, \text {cal }}(\mathrm{mg} / \mathrm{g})$ & $\mathrm{R}^{2}$ \\
\hline $\mathrm{CCAC}_{\mathrm{KOH}}$ & 4859.25 & 0.430698 & 4858.092 & 0.846 & 0.00659 & 4857.138 & 0.999 \\
\hline Adsorbent & $\mathrm{q}_{\mathrm{e}, \exp }(\mathrm{mg} / \mathrm{g})$ & $\begin{array}{l}\text { Intra-particle D } \\
\mathrm{K}_{\mathrm{ip}}\left(\mathrm{mg} / \mathrm{g} \cdot \mathrm{min}^{1 /}\right.\end{array}$ & ion & $\mathrm{C}(\mathrm{mg} / \mathrm{g})$ & $\mathrm{q}_{\mathrm{e}, \text { cal }}(\mathrm{mg} / \mathrm{g})$ & $\mathrm{R}^{2}$ & \\
\hline $\mathrm{CCAC}_{\mathrm{KOH}}$ & 4859.25 & 1.107923676 & & 4848.39 & 4859.747 & 0.8499 & \\
\hline
\end{tabular}

Source: Ukpong et al. (2020).

According to Ukpong et al. (2020), this validated the fact that "the rates of surface reaction, chemical reaction (chemisorption) and transport of crude oil from liquid to adsorbent phase was faster due to the high hydrophobic nature of the modified adsorbents" $[3,56,57]$.

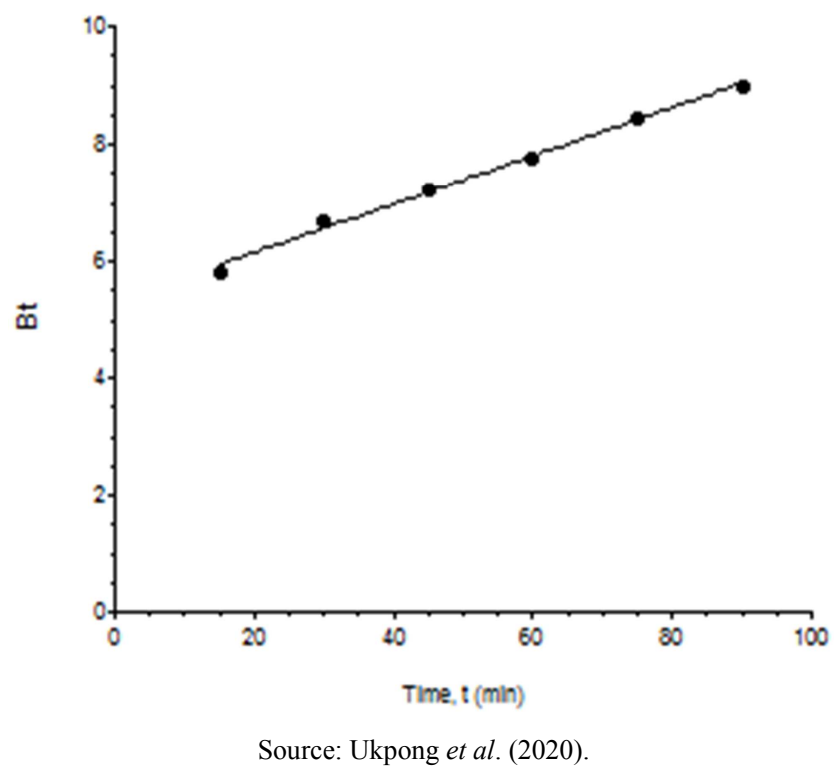

Figure 1. Boyd plot for the adsorption of crude oil onto $C \mathrm{CAC} \mathrm{KOH}_{\text {. }}$.

For intra-particle diffusion model, the larger the intercept (boundary layer effect; $\mathrm{C}$ ), the greater the contribution of the surface sorption in the rate-controlling step [58]. As elucidated by Ukpong et al. (2020), this implied that "the coefficient of determination and thickness of the boundary layer for $\mathrm{CCAC}_{\mathrm{KOH}}\left(\mathrm{R}^{2}=0.8499 ; \mathrm{C}=4848.39 \mathrm{mg} / \mathrm{g}\right)$ validated the presence of certain degree of boundary layer control over the adsorption process which also indicated that the intraparticle diffusion was not the only rate-limiting step, but other processes might as well have controlled the rate of adsorption" $[3,59]$.

Bulut and Zeki (2007) stated that "the Boyd model which is widely used for studying the mechanism of adsorption was also used to determine whether the main resistance to mass transfer was in the thin film (boundary layer) surrounding the adsorbent particle or in the resistance to diffusion inside the pores" $[3,60]$. The linearity test of the plot of $B_{t}$ against time was used to distinguish between the film and particlediffusion controlled adsorption mechanism as shown in Figure 1. A straight line plot passing through the origin indicates that the adsorption rate is governed by the particle diffusion; otherwise it is governed by the film diffusion [60]. This deviation may be due to the difference in mass transfer rate in the initial and final stages of adsorption [61]. Figure 1 showed the Boyd plot for the crude oil adsorption onto $\mathrm{CCAC}_{\mathrm{KOH}}$ to be a linear graph which does not pass through the origin, thus confirming that the adsorption mechanism was film-diffusion controlled [3].

\subsection{Developed Model}

Three parameters were used to develop a mathematical model that relates Adsorption capacity (A. C) to contact time $(t)$, initial concentration $\left(\mathrm{C}_{\mathrm{o}}\right)$ and adsorbent mass $(\mathrm{M})$ for the adsorption of crude oil to which this research work has been able to establish. For crude oil adsorption using $\mathrm{CCAC}_{\mathrm{KOH}}$, the developed adsorption coefficient $\left(\beta_{\mathrm{o}}=4124.887\right)$ and exponential constants $\left(\beta_{1}=0.040975, \quad \beta_{2}=0.002538\right.$ and $\left.\beta_{3}=0.043401\right)$ were obtained using Microsoft Excel Solver (after the iteration with the GRG protocol) as shown in Table 4.

The empirical model developed is given as Eq. (8).

$$
\text { A.C }=4124.887\left[\frac{t^{0.04098 * C_{o}}{ }^{0.00254}}{M^{0.04340}}\right]
$$


Table 4. Statistical values of the developed model for $C$ CAC ${ }_{K O H}$.

\begin{tabular}{llllll}
\hline Developed model & $\boldsymbol{\beta}_{\mathbf{0}}$ & $\boldsymbol{\beta}_{\mathbf{1}}$ & $\boldsymbol{\beta}_{\mathbf{2}}$ & $\boldsymbol{\beta}_{\mathbf{3}}$ & (O. F) \\
\hline MPSD & 4126.19000 & 0.04078 & 0.00255 & 0.04232 & 0.04340 \\
HYBRID & 4124.85100 & 0.04098 & 0.00254 & 0.04232 & $3.87513 \times 10^{-16}$ \\
ARE & 4126.19000 & 0.04078 & 0.00255 & 0.04232 & 0.04340 \\
EABS & 4126.19000 & 0.04078 & 0.00255 & 0.04340 & 0.00016 \\
SSE & 4124.85100 & 0.04098 & 0.00254 & 0.04232 & $0.40871 \times 10^{-14}$ \\
$\chi^{2}$ & 4124.85100 & 0.04098 & 0.00254 & 0.00255 & 0.04340 \\
RMSE & 4126.19000 & 0.04078 & 0.00254 & $0.97494 \times 10^{-18}$ \\
R $^{2}$ & 4124.88700 & 0.04098 & & $03529 \times 10^{-05}$ & 0.9722 \\
\hline
\end{tabular}

(O. F)-Objective function for the minimum error distribution between experimental and predicted data.

The characteristics of the developed model have been evaluated using the different statistical criteria as shown in Table 4. Table 4 showed that the value of $\mathrm{R}^{2}$ is 0.997217 and the other error functions are MPSD: $6.53655 \times 10^{-07}$, HYBRID: $3.87513 \times 10^{-16}$, ARE: $1.30633 \times 10^{-07}$, EABS: 0.000159, SSE: $9.40871 \times 10^{-14}, \chi^{2}: 3.87494 \times 10^{-18}$ and RMSE: $7.93529 \times 10^{-05}$. The values of $\mathrm{R}^{2}$ and other statistical criteria of the developed model showed a better result compared to other models used in analysing the experimental data as shown in Table 5.

\subsection{Prediction of Parameters for the Adsorption Kinetics using Error Functions}

The calculated adsorption kinetics parameters and the corresponding error functions for the minimum error distribution between the experimental data and predicted data for crude oil removal using $\mathrm{CCAC}_{\mathrm{KOH}}$ is given in Table 5.

Table 5. Predicted kinetics by minimizing the error distribution using six different error functions for $C C A C_{K O H}$.

\begin{tabular}{|c|c|c|c|}
\hline Pseudo-first order & $K_{f}(g / m g . m i n)$ & $q_{\mathrm{e}, \mathrm{cal}}(\mathrm{mg} / \mathrm{g})$ & (O. F) \\
\hline MPSD & 0.478049 & 4857.60800 & $3.44564 \times 10^{-08}$ \\
\hline HYBRID & 0.430700 & 4858.09200 & $5.74776 \times 10^{-20}$ \\
\hline ARE & 0.430929 & 4858.08900 & $1.70548 \times 10^{-09}$ \\
\hline ERRSQ & 0.457800 & 4857.77400 & $1.14961 \times 10^{-17}$ \\
\hline$\chi^{2}$ & 0.490944 & 4857.52600 & $1.93604 \times 10^{-14}$ \\
\hline RMSE & 0.497367 & 4857.49000 & $1.04420 \times 10^{-07}$ \\
\hline Pseudo-second order & $K_{\mathrm{s}}(\mathrm{g} / \mathrm{mg} \cdot \mathrm{min})$ & $q e_{, \text {cal }}(\mathrm{mg} / \mathrm{g})$ & (O. F) \\
\hline MPSD & 0.47805 & 4857.18800 & $2.52653 \times 10^{-06}$ \\
\hline HYBRID & 0.43170 & 4857.19300 & $4.07298 \times 10^{-10}$ \\
\hline ARE & 0.43093 & 4857.19200 & $4.94635 \times 10^{-07}$ \\
\hline EABS & 0.44895 & 4857.19100 & 0.00025 \\
\hline ERRSQ & 0.45780 & 4857.19000 & $2.11758 \times 10^{-22}$ \\
\hline RMSE & 0.53048 & 4857.18300 & $5.11672 \times 10^{-07}$ \\
\hline $\mathrm{R}^{2}$ & 0.00659 & 4860.57200 & 0.99946 \\
\hline
\end{tabular}

\begin{tabular}{|c|c|c|c|c|c|}
\hline Intra-particle Diffusion & $K_{\text {ip }}\left(\mathrm{mg} / \mathrm{g} \cdot \mathrm{min}^{1 / 2}\right)$ & $\mathrm{C}(\mathrm{mg} / \mathrm{g})$ & & $\mathrm{q}_{\mathrm{e}, \mathrm{cal}}(\mathrm{mg} / \mathrm{g})$ & $(\mathbf{O} . \mathrm{F})$ \\
\hline MPSD & 1.12815 & 4848.23500 & & 4857.14100 & $1.78557 \times 10^{-05}$ \\
\hline HYBRID & 1.15798 & 4847.99900 & & 4857.14100 & 0 \\
\hline ARE & 1.13827 & 4848.15500 & & 4857.14100 & $1.35813 \times 10^{-07}$ \\
\hline EABS & 1.12507 & 4848.25700 & & 4857.13900 & 0.01489 \\
\hline ERRSQ & 1.11833 & 4848.31200 & & 4857.14100 & 0 \\
\hline$\chi^{2}$ & 1.25800 & 4847.21000 & & 4857.14100 & $1.36242 \times 10^{-27}$ \\
\hline RMSE & 1.12816 & 4848.23400 & & 4857.13400 & 0.00252 \\
\hline $\mathrm{R}^{2}$ & 1.10792 & 4848.39400 & & 4857.14000 & 0.84998 \\
\hline Developed model & $\boldsymbol{\beta}_{0}$ & $\beta_{1}$ & $\boldsymbol{\beta}_{2}$ & $\beta_{3}$ & (O. F) \\
\hline MPSD & 4126.19000 & 0.04078 & 0.00255 & 0.04232 & $6.53655 \times 10^{-07}$ \\
\hline HYBRID & 4124.85100 & 0.04097 & 0.00254 & 0.04340 & $3.87513 \times 10^{-16}$ \\
\hline ARE & 4126.19000 & 0.04078 & 0.00255 & 0.04232 & $1.30633 \times 10^{-07}$ \\
\hline EABS & 4126.19000 & 0.04078 & 0.00255 & 0.04232 & 0.00016 \\
\hline SSE & 4124.85100 & 0.04098 & 0.00254 & 0.04340 & $9.40871 \times 10^{-14}$ \\
\hline$\chi^{2}$ & 4124.85100 & 0.04098 & 0.00254 & 0.04340 & $3.87494 \times 10^{-18}$ \\
\hline RMSE & 4126.19000 & 0.04078 & 0.00254 & 0.04232 & $7.93529 \times 10^{-05}$ \\
\hline $\mathrm{R}^{2}$ & 4124.88700 & 0.04098 & 0.00254 & 0.04340 & 0.99722 \\
\hline
\end{tabular}


(O. F)-Objective function for the minimum error distribution between experimental and predicted data.

From Table 5, the error functions corresponding to the minimum deviations between the experimental kinetics data and calculated data for adsorption kinetics using $\mathrm{CCAC}_{\mathrm{KOH}}$ suggested that Pseudo-second order model was the best kinetics model with the highest $\mathrm{R}^{2}$ value of 0.999464 and the least value for other error functions. Intra-particle diffusion model had $\mathrm{R}^{2}$ value of 0.849982 and Pseudo-first order model had the least $\mathrm{R}^{2}$ value of 0.846472 .

These results emphasize the need for the use of statistical error function to better evaluate the adsorption models, as previously reported by $[62,63]$. In addition, it was verified that the calculated $q_{\mathrm{e}}$ values found in the pseudo-secondorder model for Table 3 was in conformity with the experimental $q_{\mathrm{e}}$ values which indicated that the pseudosecond-order kinetic model should be considered during the adsorption process of crude oil removal by $\mathrm{CCAC}_{\mathrm{KOH}}$. By analysing the values of the kinetic parameters as illustrated in Table 3 , it should be noted that the $\mathrm{k}_{\mathrm{s}}$ values strongly depend on the initial concentration, since its units is $\mathrm{g} /(\mathrm{mg}$. $\mathrm{min})$.

\section{Conclusions}

The adsorption kinetic study showed that the adsorption of crude oil followed a pseudo-second order model for $\mathrm{CAC}_{\mathrm{KOH}}\left(\mathrm{R}^{2}=0.999\right)$ compared to pseudo-first order kinetic model and intra-particle diffusion model and was controlled by film diffusion and governed by the internal transport mechanism. The developed mathematical model was validated by fitting it into the experimental data which gave a better result of correlation coefficient of 0.9972 for $\mathrm{CCAC}_{\mathrm{KOH}}$ when compared to pseudo first order model, pseudo second order model and intra-particle diffusion model. Hence, an empirical model developed using multivariate numerical optimization method can be used for design of industrial treatment plant.

\section{Declarations of Competing Interest}

The authors declare that they have no competing interests.

\section{Acknowledgements}

The authors acknowledge Dr. Uwem Inyang, Dr. Anietie Okon and Engr. Peter Asangusung, all from the Department of Chemical and Petroleum Engineering, University of Uyo, Uyo, Akwa Ibom State, Nigeria, for their immense contributions towards the success of this research work.

\section{References}

[1] Abdelwahab, O. (2014). Assessment of raw luffa as a natural hollow oleophilic fibrous sorbent for oil spill clean-up. National Institute of Oceanography and Fisheries, Alexandria, Egypt. Alexandria Engineering Journal, 53: 213-218.
[2] Freeman, R. E. (2012). Stakeholder theory of modern corporation business ethics. The Controversy, 38-48p.

[3] Ukpong, A. A., Gumus, R. H. and Oboh, I. O. (2020). Adsorption Studies of Oil Spill Clean-up Using Coconut Coir Activated Carbon (CCAC). American Journal of Chemical Engineering. 8 (2): 36-47.

[4] Allan, S. E., Smith, B. W., Anderson, K. A. (2012). Impact of the deep-water horizon oil spill on bioavailable polycyclic aromatic hydrocarbons in Gulf of Mexico coastal waters. Environmental Science and Technology, 46: 2033-2039.

[5] Nwilo, C. P. and Badejo, T. O (2005). Oil spill problems and management in the Niger Delta. International Oil Spill Conference, Miami, Florida, $7 \mathrm{p}$.

[6] Egbe, R. E. (2010). Environmental challenges of oil spillage for families in oil producing communities of the Niger Delta region. International Journal of Modern Engineering Research, 3 (6): 3336-3342.

[7] Kingston, P. F. (2002). Long-term environmental impact of oil spills. Bulletin of Spill Science and Technology, 7: 53-61.

[8] Jernelov, A. (2010). The Threats from Oil Spills: Now, Then, and in the Future, $A M B I O, 39: 353-366$.

[9] Polka, M., Bozena, K., Marek, W. and Joanne, R. (2015). Efficiency analysis of the sorbents used to adsorb the vapours of petroleum products during rescue and fire-fighting actions. Przem. Chemistry Journal, 1: 109-113.

[10] Ahmad, A. A., Hameed, B. H. and Aziz, N. (2006). Adsorption of direct dye on palm ash: Kinetic and equilibrium modelling. Journal of Hazardous Materials, 94: 1-10.

[11] Chakraborty, S., De, S., Dascupta, S. and Basu, J. K. (2005). Adsorption study for the removal of basic dye: experimental and modelling. Chemosphere, 58: 1079-1089.

[12] Mathur, A. K., Majumder, C. B. and Chatterjee, S. (2007). Combined removal of BTEX in air stream by using mixture of sugar cane bagasse, compost and GAC as bio-filter media. Journal of Hazardous Materials, 148: 64-74.

[13] Bina, B., Amin, M. M., Rashidi, A. and Pourzamani, H. (2014). Water and wastewater treatment from BTEX by carbon nanotubes and nano- $\mathrm{Fe}^{1}$. Water Resources, 41 (6): 719-727.

[14] Egbuchunam, T. O., Obi, G., Okieimen, F. E. and Tihminlioglu, F. (2016). Removal of BTEX from aqueous solution using organokaolinite. International Journal of Applied Environmental Sciences, 11 (2): 505-513.

[15] Jaynes, W. F. and Vance, G. F. (1999). Sorption of benzene, toluene, ethylbenzene and xylene (BTEX) compounds by hectorite clays exchanged with aromatic organic cations. Clays and Clay Minerals, 47 (3): 358-365.

[16] Senthilkumaar, S., Kalaamani, P., Porkodi, K., Varadarajan, P. R. and Subburaam, C. V. (2006). Adsorption of dissolved Reactive red dye from aqueous phase onto activated carbon prepared from agricultural waste. Bioresource Technology, 97: 1618-1625.

[17] Senthilkumaar, S., Kalaamani, P., Porkodi, K., Varadarajan, P. R. and Subburaam, C. V. (2005). Adsorption of dissolved Reactive red dye from aqueous phase onto activated carbon prepared from agricultural waste. Bioresource Technology, 97: 1618-1625. 
[18] Kalavthy, M. H., Karthikeyan, T., Rajgopal, S. and Miranda, L. R. (2005). Kinetic and isotherm studies of $\mathrm{Cu}(\mathrm{II})$ adsorption onto $\mathrm{H}_{3} \mathrm{PO}_{4}$ activated rubber wood sawdust. Journal of Colloids Interface Science, 292: 354-362.

[19] Tseng, R. L. and Tseng, S. K. (2006). Preparation of high surface are carbons from corncob with $\mathrm{KOH}$ etching plus $\mathrm{CO}_{2}$ gasification for adsorption of dyes and phenols from water. Journal of Colloid and Interface Science: Physicochemical Engineering Aspect, 279: 69-78.

[20] Hameed, B. H., Din, A. T. M. and Ahmad, A. L. (2007). Adsorption of methylene blue onto bamboo-based activated carbon; Kinetics and equilibrium studies. Journal of Hazardous Materials, 141: 819-825.

[21] Tan, I. A. W., Hameed, B. H. and Ahmed, A. L. (2007). Equilibrium and kinetic studies on basic dye adsorption by oil palm fibre activate carbon. Journal of Chemical Engineering, 2 (127): 111-119.

[22] Iakovleva, E. and Sillanpää, M. (2013). The use of low cost adsorbents for wastewater purification in Mining industries. Environmental Science and Pollution Research, 20 (11): 7878-7899.

[23] Edgar, T. F. and Himmelblau, D. M. (2001). Optimization of Chemical Processes. 2nd Edition, McGraw-Hill Chemical Engineering Series. New York, 1323p.

[24] Hanna, O. T. and Sandall, O. C. (1995). Computerization Methods in Chemical Engineering, Printice-Hall International, New Jessey, 1469p.

[25] Kumar, K. V. (2006). Comparative analysis of linear and nonlinear method of estimating the sorption isotherm parameters for malachite green onto activated carbon. Journal of Hazardous Materials, 136 (2): 197-202.

[26] Kumar, K. V., Porkodi, K. and Rocha, F. (2008b). Comparison of various error functions in predicting the optimum isotherm by linear and non-linear regression analysis for the sorption of basic red 9 by activated carbon. Journal of Hazardous Materials, 150 (1): 158-165.

[27] Kumar, K. V., Porkodi, K. and Rocha, F. (2008a). Isotherms and thermodynamics by linear and non-linear regression analysis for the sorption of methylene blue onto activated carbon: Comparison of various error functions. Journal of Hazardous Materials, 151 (2-3): 794-804.

[28] Lataye, D. H., Mishra, I. M. and Mall, I. D. (2008). Adsorption of 2-picoline onto bagasse fly ash from aqueous solution, Chemical Engineering Journal, 138 (1-3): 35-46.

[29] Kumar, K. V. and Sivanesan, S. (2006). Pseudo second order kinetics and pseudo isotherms for malachite green onto activated carbon: comparison of linear and non-linear regression methods. Journal of Hazardous Materials, 1 (5): 721-726.

[30] Okon, A. N., Udoh, F. D. and Appah, D. (2015). Empirical Wellhead Pressure - Production Rate Correlations for Niger Delta: Oil Wells. Paper Presented at the Society of Petroleum Engineers Nigeria. Annual Internal Conference and Exhibition, Lagos, Nigeria, 4 (6), 1-17.

[31] Wei, J. (2013). Multivariate numerical optimization. Lecture note.

[32] https://studentsportalen.uu.se/uusp-filearea-tool. (Retrieved on $25^{\text {th }}$ May, 2019).

[33] Smyth, G. K. (2015). Optimization and non-linear equations. Statistics reference online, 1: 1-9.

[34] Inyang, U. E., Etuk, B. R. and Oboh, I. O. (2019). Mathematical and kinetic modelling for convective hot air drying of sweet potatoes (Ipomoea batatas L). American Journal of Chemical Engineering, 7 (1): 22-31.

[35] Olufemi, B. A., Jimoda, L. A. and Agbodike, N. F. (2014). Adsorption of crude oil using meshed corncobs. Asian Journal of Applied Science and Engineering, 3: 63-75.

[36] Aryafar, A., Mikaeil, R., Doulati Ardejani, F. Shaffiee Haghshenas, S. and Jafarpour, A. (2019). Application of non-linear regression and soft computing techniques for modeling process of pollutant adsorption from industrial wastewaters. Journal of Mining and Environment, 10 (2): 327-337.

[37] Mansur, M. B. and Maria, M. E. (2016). Mathematical modelling of batch adsorption of manganese onto bone char. Brazilian Journal of Chemical Engineering, 33 (2): 373-382.

[38] Sicupira, D. C., Silva, T. T., Leao, V. A. and Mansur, M. B. (2014). Batch removal of manganese from acid mine drainage using bine char. Brazilian Journal of Chemical Engineering, 31: 195-204.

[39] Ebrahim, S. E. (2013). Modelling the removal of phenol by natural zeolitein batch and continuous adsorption systems. Journal of Babylon University/Engineering Sciences, 21 (1): $1-14$.

[40] Tan, K. L. and Hameed, B. H. (2017). Insight into the adsorption kinetics models for the removal of contaminants from aqueous solutions. Journal of the Taiwan Institute of Chemical Engineers. 74: 25-48.

[41] Ho, Y. S. and McKay, G. (1998). Kinetic models for the sorption of dye from aqueous solution by wood. Adsorption Science Technology Journal, 16: 243-255.

[42] Yang, X. and Al-Duri, B. (2005). Kinetic modelling of liquidphase adsorption of reactive dyes on activated carbon. Journal of Colloid and Interface Science, 287 (1): 25-34.

[43] Ejikeme, P. C. N., Ejikeme, E. M., and Okonkwo, G. N. (2014). Equilibrium, kinetic and thermodynamic studies on basic dye adsorption using composite activated carbon. International Journal of Technical Research and Applications, 2 (4): 96-103.

[44] Dural, M. U., Cakas, L., Papagergiou, S. K. and Katsaros, F. K. (2011). Methylene blue adsorption on activated carbon prepared from Posidonia Oceanica (L) dead leaves: Kinetics and equilibrium studies. Chemical Engineering Journal, 168: $77-85$.

[45] Maamoud, D. K., Mohasalleh, M. A., Karima, W. A., Idris, A. and Abidin, Z. Z. (2012). Batch adsorption of basic dye using acid treated kenaf fibre char: Equilibrium, kinetic and thermodynamic studies. Chemical Engineering Journal, 181: 449-457.

[46] Kajjumba, G. W., Aydın, S. and Güneysu, S. (2018). Adsorption isotherms and kinetics of vanadium by shale and coal waste. Adsorption Science and Technology, 36 (3-4): 936-952. 
[47] Tang, H., Zhou, W. and Zhang, L. (2012). Adsorption isotherms and kinetics studies of malachite green on chitin hydrogels. Journal of Hazardous Materials, 209-210: 218-225.

[48] Mane, V. S., Deo, M. I. and Chandra, S. V. (2007). Kinetic and equilibrium isotherm studies for the adsorptive removal of Brilliant Green dye from aqueous solution by rice coir ash. Journal of Environmental Management, 84 (4): 390-400.

[49] Porter, J. F., McKay, G. and Choy, K. H. (1999). The prediction of sorption from a binary mixture of acidic dyes using single-and mixed-isotherm variants of the ideal adsorbed solute theory. Chemical Engineering Science, 54 (24): 5863-5885.

[50] Saadi, R., Saadi, Z., Fazaeli, R. and Fard, N. E. (2015). Monolayer and multilayer adsorption isotherm models for sorption from aqueous media. Korean Journal of Chemical Engineering, 32 (5): 787-799.

[51] Ng, J. C. Y., Cheung, W. H. and McKay, G. (2002). Equilibrium studies of the sorption of $\mathrm{Cu}$ (II) ions onto chitosan. Journal of Colloid and Interface Science, 255 (1): 64-74.

[52] Kundu, S. and Gupta, A. K. (2006). Arsenic adsorption onto iron oxide coated cement (IOCC): Regression analysis of equilibrium data with several isotherm models and their optimization. Chemical Engineering Journal, 122 (1-2): 93-106.

[53] Karadag, D., Koc, Y., Turan, M. and Ozturk, M. (2007). A comparative study of linear and non-linear regression analysis for ammonium exchange by clinoptilolite zeolite. Journal of Hazardous Materials, 144 (1-2): 432-437.

[54] Ho, Y. S. (2006). Second-order kinetic model for the sorption of cadmium onto tree fern: A comparison of linear and nonlinear methods, Water Resource, 40: 119-125.

[55] Rivas, F. J., Beltr'an, F. J., Gimeno, O., Frades, J. and Carvalho, F. (2006). Adsorption of landfill leachates onto activated carbon: Equilibrium and kinetics. Journal of Hazardous Materials, 131 (1-3): 170-178.
[56] Boulinguiez, B., Le Cloirec, P. and Wolbert, D. (2008). Revisiting the determination of Langmuir parametersapplication to tetrahydrothiophene adsorption onto activated carbon, Journal of the American Chemical Society, 24 (13): 6420-6424.

[57] Tan, I. A. W and Hameed, B. H. (2010). Adsorption isotherms, kinetics, thermodynamics and desorption studies of basic dye on activated carbon derived from oil palm empty fruit bunch. Journal of Applied Sciences, 10 (21): 2565-2571.

[58] Onwuka, J. C., Agbaji, E. B., Ajibola, V. O. and Okibe, F. G. (2018). Treatment of crude oil contaminated water with chemically modified natural fibre. Applied Water Science Journal, 8 (86): 1-10.

[59] Eba, F., Gueu, S., Eya'A-Mvongbote, A., Ondo, J. A., Yao, B. K., Ndong, N. J. and Kouya, B. R. (2010). Evaluation of the absorption capacity of the natural clay from Bikougou (Gabon) to remove $\mathrm{Mn}(\mathrm{II})$ from aqueous solution. International Journal of Engineering and Science Technology, 2 (10): 50015016.

[60] Srivastava, V. C., Swammy, M. M., Mall, I. D., Prasad, B. and Mishra, I. M. (2006). Adsorptive removal of phenol by bagasse fly ash and activated carbon: equilibrium, kinetics and thermodynamics. Colloids Surface and Physicochemical Engineering Aspects, 272: 89-104.

[61] Bulut, Y. and Zeki, T. (2007). Removal of heavy metals from aqueous solution by sawdust adsorption. Journal of Environmental Science, 19: 160-166.

[62] Mohanty, K., Das, D. and Biswas, M. N. (2005). Adsorption of phenol from aqueous solutions using activated carbons prepared from tectona grandis sawdust by $\mathrm{ZnCl}_{2}$ activation. Chemical Engineering Journal, 115: 121-131.

[63] Jacques, R. A., Bernardi, R., Caovila, M., Lima, E. C., Pavan, F. A., Vaghetti, J. C. P. and Airoldi, C. (2007). Removal of $\mathrm{Cu}$ (II), $\mathrm{Fe}(\mathrm{III})$ and $\mathrm{Cr}$ (III) from aqueous solution by aniline grafted silica gel, Separation Science and Technology, 42: 591-609. 